\title{
Keadilan Dalam Perspektif Ekonomi Islam
}

\author{
Alifta Salfitra \\ program studi Ilmu al Qurán dan Tafsir \\ Sekolah Tinggi Ilmu Ushuluddin Darul Quran \\ Email: syalfitraalifta@gmail.com \\ Auliya Izzah Hasanah \\ Sekolah Tinggi Ilmu Ushuluddin Darul Quran, Bogor \\ Email: auliyaizzahhasan@gmail.com \\ Rachmad Risqy Kurniawan, SEI, MM \\ Sekolah Tinggi Ilmu Ushuluddin Darul Quran Mulia, Bogor \\ Email: rah.rizqy@gmail.com
}

\begin{abstract}
This study aims to examine the justice that exists in the perspective of Islamic economics. Economic activities in Islam must be based on the principle of justice to create prosperity and social welfare. This research is a library research with analytical interpretation method. Based on this research, it can be concluded that fairness must be possessed by every human being to uphold the truth without exception. And Islam has commanded us to be fair to each other. As the word of Allah SWT in Surah al Maidah verse 8. Allah SWT emphasizes that "Never hate someone, make you unfair because justice is closer to piety." So, let's not hate someone and not be fair to him. Indeed, doing justice is the closest way to achieving the goal of piety to Allah. Allah sent down Islam as a source and guide for human life, in which emphasizes on us to uphold justice for all, including even those we hate.
\end{abstract}

\section{Keywords: Islamic Economics, Justice}

Abstrak: Penelitian ini bertujuan untuk mengkaji keadilan yang ada dalam perspektif ekonomi Islam. Kegiatan ekonomi dalam Islam harus berdasarkan prinsip keadilan untuk mewujudkan kemakmuran maupun kesejahteraan masyarakat. Penelitian ini merupakan penelitian kepustakaan (library research) dengan metode penafsiran analitik. Berdasarkan penelitian ini maka dapat disimpulkan bahwa sifat adil itu harus dimiliki oleh setiap manusia untuk menegakkan kebenaran tanpa terkecuali. Dan Islam telah memerintahkan kita untuk berlaku adil terhadap sesama. Sebagaimana firman Allah SWT dalam surat al Maidah ayat 8. Allah SWT menegaskan bahwa "'janganlah sekali kali kebencian terhadap suatu, menjadikanmu tidak adil karena adil itu lebih dekat kepada taqwa.' Jadi, janganlah kita membenci kepada seseorang dan tidak berlaku adil terhadapnya. Sesungguhnya berlaku adil adalah jalan yang terdekat untuk mencapai tujuan bertaqwa kepada Allah. Allah yang menurunkan Islam sebagai sumber dan pedoman bagi kehidupan manusia, yang didalamnya menekankan kepada kita untuk menegakkan keadilan untuk semua termasuk kepada orang yang kita benci sekali pun.

Kata kunci: Ekonomi Islam, Keadilan 


\section{Pendahuluan}

Pada umumnya manusia menghendaki kesejahteraan dalam hidupnya. Baik kesejahteraan individu, kelompok, atau bahkan yang lebih besar. Masalah ekonomi selalu menarik perhatian individu dan masyarakat. Dalam pemenuhan kebutuhan ekonomi berbagai usaha dilakukan dan berbagai cara difungsikan untuk mengatasi atau memecahkan masalah ini. Sebagian usaha mereka berhasil hingga mencapai puncaknya, sebagian lagi kehilangan arah dan keseimbangan. Roda kehidupan selalu berputar, aktivitas ekonomi manusia memungkinkan terjadinya ketimpangan atau ketidakseimbangan. Hak-hak seseorang bisa saja terkekang, kepentingan terabaikan, sebagaimana terjadi dalam sistem ekonomi kapitalis dan ekonomi sosialis. ${ }^{1}$

Dalam sistem kapitalis memiliki beberapa kecenderungan diantaranya: kebebasan memiliki harta secara perorangan, persaingan bebas, serta ketimpangan ekonomi. Dengan adanya ketimpangan ekonomi maka terjadi ketidakseimbangan pada masyarakat seperti ketidakadilan. Dan sistem ini melibatkan individu atau perorangan. Karena setiap individu nya, semua orang itu bebas bersaing untuk memperoleh laba sebesar-besarnya. ${ }^{2}$

Sistem ekonomi sosial merupakan bentuk resistensi dari sistem ekonomi kapitalis yang dituding sebagai penyebab tidak tercapainya kesejahteraan yang merata. Jika sistem kapitalis sepenuhnya menyerahkan siklus ekonomi pada mekanisme pasar yang berkembang, maka dalam sistem ekonomi sosialis pemerintah punya andil besar dalam mengatur roda perekonomian di sebuah negara. Mulai dari perencanaan, pelaksanaan, sampai pengawasan terhadap rantai perekonomian masyarakat. ${ }^{3}$ Dengan begitu sistem ini mementingkan kemakmuran dan kesejahteraan masyarakat. yang mana, hal perekenomian sudah diatur dan ditanggung oleh negara.

Kedua sistem ekonomi tersebut tentunya memiliki kelebihan dan kekurangan masing masing. Hal yang paling mendasar dari kedua sistem ini adalah masih ada aspek kedzholiman. Pada sistem ekonomi kapitalis, masyarakat kecil selaku buruh mendapatkan perlakuan semena-mena dari pemilik modal, terutama kebijakan upah dan lain sebagainya. Sedangkan pada sistem ekonomi sosialis, hak hak individu yang seharusnya dapat ia miliki tidak diperbolehkan oleh pemerintah. ${ }^{4}$

Konsep kapitalis tentang keadilan sosio-ekonomi dan pemerataan pendapatan, tidak sama dengan konsep keadilan ekonomi dalam Islam, karena tidak didasarkan pada komitmen spiritual dan persaudaraan (ukhuwah) sesama manusia. Komitmen penegakkan keadilan sosio-ekonomi lebih merupakan akibat dari tekanan kelompok. Karenanya, sistem kapitalisme terutama yang berkaitan dengan uang/perbankan, tidak dimasukkan untuk mencapai tujuan tujuan keadilan sosio-ekonomi yang berdasarkan nilai spiritual dan persaudaraan universal. Sehingga tidak aneh, apabila uang masyarakat yang ditarik oleh bank konvensional (kapitalisme) dominan hanya digunakan oleh para pengusaha besar (konglomerat). Lembaga perbankan tidak dinikmati oleh rakyat kecil yang menjadi mayoritas penduduk sebuah negara.

\footnotetext{
${ }^{1}$ Wing Redy Prayuda, Keadilan Ekonomi Dalam Perspektif Hukum Islam, Al Mustashfa, Vol. 2, No. 1, (2017)

${ }^{2}$ Indra Sholeh Husni, Konsep Keadilan Ekonomi Islam Dalam Sistem Ekonomi Islam, Sebuah Kajian Konsepsional, Islamic Economics Journal Vol 6 No.1, (2020)

${ }^{3}$ Itang,. Adib Daenuri, Sistem Ekonomi Kapitalis, Sosialis, dan Islam, Tazkiya Vol 18 No.1 (2017)

${ }^{4}$ Muhammad Thoin, Konsep Ekonomi Islam Jalan Tengah (Kapitalis-Sosialis), Jurnal Ilmiah Ekonomi Islam, Vol.1, No. 3, (2015)
} 
Fenomena ini semakin jelas terjadi di Indonesia. Akibatnya yang kaya semakin kaya, dan yang miskin semakin miskin. Dan ketidakadilan pun semakin lebar. ${ }^{5}$

Hal tersebut mendorong untuk terwujudnya konsep sistem ekonomi yang baru. Dengan demikian, adanya ekonomi Islam diharapkan dapat menjadi solusi dari permasalahan yang ada. Sehingga, harapan terwujudnya sistem ekonomi yang berkeadilan menuju kemakmuran dan pemerataan.

Dari pembahasan diatas, penulis akan mengkaji lebih dalam guna mengetahui makna keadilan terhadap sesama menurut al Qurán surat al Maidah ayat 8 dalam perspektif ekonomi Islam. Penelitian ini merupakan penelitian kepustakaan (library research) dengan menggunakan literatur (kepustakaan) sebagai sumber antara lain kitab tafsir dan artikel ilmiah pendukung lainnya, metode penelitian ini adalah metode penelitian tahlili (analitik) yaitu metode penafsiran al Qurán yang berusaha menjelaskan al Qurán dengan menguraikan berbagai seginya dan menjelaskan apa yang dimaksud oleh al Qurán. Dari penelitian ini, akan dihasilkan bagaimana caranya kita memahami makna keadilan, dan bagaimana konsep keadilan dalam ekonomi Islam.

\section{Keadilan Dalam Perspektif Ekonomi Islam}

Adil dalam Kamus Besar Bahasa Indonesia yang berarti sama berat, tidak berat sebelah, tidak memihak. Dan keadilan yang berarti sifat (perbuatan, perlakuan, dan sebagainya) yang adil. ${ }^{6}$ Keadilan adalah penilaian dan memberikan kepada siapapun sesuai dengan apa yang menjadi haknya. ${ }^{7}$

Keadilan dalam bahasa Arab ' 'adl' yang artinya bersikap dan berlaku dalam keseimbangan. Kesimbangan meliputi keseimbangan antara hak dan kewajiban dan keserasian dengan sesama makhluk. Keadilan pada hakikatnya adalah memperlakukan seseorang atau orang lain sesuai haknya atas kewajiban yang telah dilakukan. Yang menjadi hak setiap orang adalah diakui dan diperlakukan sesuai harkat dan martabatnya yang sama derajatnya dimata Allah SWT. Hak hak manusia adalah hak hak yang diperlukan manusia bagi kelangsungan hidupnya didalam masyarakat. ${ }^{8}$

Komitmen Islam yang besar pada persaudaraan dengan keadilan menuntut agar sumber daya dimanfaatkan untuk mewujudkan maqashid syari'ah, yakni pemenuhan kebutuhan hidup manusia, terutama kebutuhan dasar (primer), seperti sandang, pangan, papan, pendidikan dan kesehatan. Persaudaraan dan keadilan juga menuntut agar semua sumber daya didistribusikan secara adil kepada seluruh rakyat melalui kebijakan yang adil. ${ }^{9}$

Keadilan menurut Muhammad Imarah sebagaimana yang dikutip oleh Zaki Fuad Chalil bahwa adalah suatu keharusan dalam ajaran agama Isalm karena merupakan satu diantara unsur vital kehidupan sosial dan kemanusiaan. Keadilan bukan sekedar hak,

\footnotetext{
5 Agustianto, Keadilan Ekonomi Dalam Islam, Iqtishad consulting, (https://iqtishadconsulting.com/content/read/blog/artikel/keadilan-ekonomi-dalam-islam) diakses 6/10/2015

6 Badan Pengembangan dan Pembinaan Bahasa Kementerian Pendidikan dan Kebudayaan Republik Indonesia, Kamus Besar Bahasa Indonesia Edisi Kelima, Jakarta: Balai Pustaka, 2017.

7 Nurwino wajib, Keadilan Dalam Konteks Perkembangan Paradigma Pembangunan, Kotaku.pu.go.id, (http://kotaku.pu.go.id:8081//wartaarsipdetil.asp?mid=8395\&catid=2\&) diakses 26/10/2016

${ }^{8}$ Afifa Rangkuti, Konsep Keadilan Dalam Perspektif Islam, Tazkiya, Vol. 4 No. 1, (2017)

${ }^{9}$ Agustianto, Keadilan Ekonomi Dalam Islam, Iqtishad consulting,

(https://iqtishadconsulting.com/content/read/blog/artikel/keadilan-ekonomi-dalam-islam) diakses 6/10/2015
} 
tetapi juga ketentuan wajib yang diciptakan Allah bagi semua manusia tanpa pengecualian termasuk dalam kegiatan ekonomi dalam Islam. ${ }^{\mathbf{1 0}}$

Ekonomi Islam juga kerap disebut dengan ekonomi syari'ah. Kedua istilah tersebut merujuk pada makna yang sama dan hanya berbeda pada pemakaian kata. Dan ekonomi Islam yang merupakan sistem ekonomi syari'ah itu berdiri tegak pada asas asas kebersamaan dan keadilan dalam mencapai tujuan.

Pengertian ekonomi Islam atau ekonomi syari'ah secara umum adalah ilmu yang mempelajari perilaku manusia dalam usahanya memenuhi kebutuhan hidup dengan berdasarkan syari'at atau nilai nilai ketuhanan. Dan tujuan utama dari sistem ekonomi syari'ah (ekonomi Islam) selaras dengan tujuan dari penerapan syari'at (hukum) agama Islam, yaitu untuk mencapai tatanan yang baik serta terhormat sehingga menciptakan kebahagiaan dalam lingkup dunia dan akhirat, hal ini menunjukkan bahwa masalah ekonomi juga menjadi perhatian dalam agama Islam. ${ }^{11}$

Tauhid yang menjadi pondasi utama dalam ekonomi Islam. Mempunyai hubungan kuat dengan konsep sosio-ekonomi dan persaudaraan. Ekonomi tauhid yang mengajarkan bahwa Allah sebagai pemilik mutlak dan manusia hanya sebagai pemegang amanah, mempunyai konsekuensi, bahwa didalam harta yang dimiliki setiap individu terdapat hak hak orang lain yang harus dikeluarkan sesuai dengan perintah Allah. Berupa zakat, infaq, dan sedekah untuk melaksanakan perindustrian pendapatan yang sesuai dengan konsep persaudaraan umat manusia. ${ }^{\mathbf{1 2}}$

Kebijakan distribusi dalam sistem ekonomi Islam menjunjung tinggi nilai keadilan yang didasarkan pada konsep distribusi dalam al Qur'an surah al Hasr agar kekayaan tidak berkumpul hanya pada satu kelompok saja. Menurut Quraish Shihab ayat tersebut bermaksud untuk menegaskan bahwa harta benda hendaknya jangan hanya menjadi milik dan kekuasaan sekelompok manusia. Harta benda harus beredar di masyarakat sehingga dapat dinikmati oleh semua anggota masyarakat dengan tetap mengakui hak kepemilikkan dan melarang monopoli, karena sejak awal Islam menetapkan bahwa harta memiliki fungsi sosial. ${ }^{\mathbf{1 3}}$

Keadilan adalah sebuah ketentuan yang diwajibkan oleh Allah SWT untuk semua manusia di dunia tanpa pengecualian. Islam memandang keadilan adalah sebuah ketentuan yang wajib dan mutlak sebagai salah satu unsur penting dalam kehidupan sosial dan kemanusiaan. ${ }^{14}$

Dalam memelihara keseimbangan serta menjaga hubungan antara tuhan dan manusia, Islam juga membentuk keseimbangan hubungan antara manusia dengan manusia lainnya. Keseimbangan tersebut dibutuhkan untuk melindungi hubungan yang sudah baik dari dampak buruk yang ditimbulkan oleh perilaku yang berlebihan dalam transaksi jual beli atau dalam kegiatan ekonomi. Itulah sebabnya mengapa dalam Islam

\footnotetext{
10 Zaki Fuad Chalil, Pemerataan Distribusi Kekayaan Dalam Ekonomi Islam (Jakarta: Penerbit Erlangga, 2009) h. 191, Syaakir Sofyan, Nilai Keadilan Dalam Ekonomi Syariah, Jurnal Studi Ilmu Syariah dan Hukum, Bilancia Jurnal Studi Ilmu Syariah dan Hukum Vol. 3 No. 2, (2019)

11 Marhamah Ika Putri, Apa Itu Ekonomi Islam Dan Tujuannya: pengertian menurut para ahli, Tirto.id, (https://tirto.id/apa-itu-ekonomi-islam-dan-tujuannya-pengertian-menurut-para-ahli-gik3) diakses 23/9/2021

12 Suryani, Keadilan Ekonomi Dalam Perspektif Ekonomi Syariah, Maksimum Vol 2 No.1, (2011)

${ }^{13}$ M. Quraish Shihab, Tafsir al-Misbah, vol 14 (Jakarta: Lentera hati, 2002), h. 112-113

${ }^{14}$ Muhammad Imarah, Islam dan Keamanan sosial, terj. Abdul Hayyie al-Kattani (Jakarta: Gema insani press, 1998), h. 116
} 
sangatlah penting dalam menciptakan keadilan pada semua aspek kehidupan manusia bukan hanya pada satu aspek saja. ${ }^{15}$

Secara umum, ekonomi Islam didefinisikan sebagai suatu cabang ilmu pengetahuan yang berupaya memandang,meneliti, dan akhirnya menyelesaikan permasalahan permasalahan ekonomi dengan cara Islami yang bersumber dari al Qur'an, as sunnah, ijma', dan qiyas.

Karena didasarkan pada nilai nilai ilahiah, sistem ekonomi Islam tentu saja akan berbeda dengan sistem ekonomi kapitalis dan juga berbeda dengan sistem ekonomi sosialis yang didasarkan pada ajaran sosialisme, memang dalam beberapa hal, sistem ekonomi Islam merupakan kompromi antara kedua sistem tersebut, namun dalam banyak hal sistem ekonomi Islam memiliki sifat sifat baik dari kapitalisme dan sosialisme, namun terlepas dari sifat buruknya. ${ }^{16}$

Keadilan merupakan pilar terpenting dalam ekonomi Islam, Allah menurunkan Islam sebagai sistem kehidupan bagi seluruh umat manusia, menekankan pentingnya penegakkan keadilan dalam setiap sektor, baik ekonomi, politik maupun sosial. Komitmen al Qur'an tentang penegakkan keadilan sangat jelas. Hal itu terlihat dari penyebutan kata keadilan dalam al Qur'an mencapai lebih dari seribu kali. Keadilan ekonomi Islam didasarkan atas konsep persaudaraan universal sesama manusia. Al Qur'an secara eksplisit menekankan pentingnya keadilan dan persaudaraan tersebut. Menurut M.Umer Chapra, sebuah masyarakat Islam yang ideal mesti mengaktualisasikan keduanya secara bersamaan, karena keduannya merupakan dua sisi yang sama yang tidak bisa dipisahkan. Dengan demikian, kedua tujuan ini terintegrasi sangat kuat ke dalam ajaran agama Islam sehingga realisasi nya menjadi komitmen spiritual (ibadah) bagi masyarakat Islam. ${ }^{17}$

Adil yang dimaknai seimbang, tidak berpihak, dan memberikan hak kepada orang yang berhak menerimanya tanpa sedikitpun dikurangi, dan menempatkan segala sesuatu pada tempatnya. Dan mengucapkan kalimat yang benar tanpa ditakuti kecuali Allah SWT. Kemudian ia menetapkan suatu kebenaran terhadap masalah masalah untuk dipecahkan sesuai dengan aturan yang ditetapkan agama. Sehingga perbuatan adil adalah suatu tindakan yang berdasar pada kebenaran. ${ }^{18}$ Dalam firman Allah surat al Maidah: 8 yang memerintahkan kita untuk menegakkan (kebenaran) dan juga berlaku adil adil terhadap sesama.

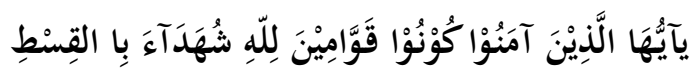

'Hai orang orang yang beriman, hendaklah kamu menjadi orang orang yang selalu menegakkan (kebenaran) karena Allah.',

\footnotetext{
${ }^{15}$ Harun Nasution dan Bahtiar Effendy, Hak Asasi Manusia Dalam Islam (Jakarta: Yayasan obor Indonesia, 1995), h. 218

${ }^{16}$ Itang,. Adib Daenuri, Sistem Ekonomi Kapitalis, Sosialis, dan Islam, Tazkiya Vol 18 No.1 (2017)

17 Agustianto, Keadilan Ekonomi Dalam Islam, Iqtishad consulting, (https://iqtishadconsulting.com/content/read/blog/artikel/keadilan-ekonomi-dalam-islam) diakses 6/10/2015

18 Rendra Widyakso, Konsep Keadilan Menurut Al Qur'an, badilag.mahkamahagung.go.id, (https://badilag.mahkamahagung.go.id/artikel/publikasi/artikel/konsep-keadilan-menurut-al-qur-an-rendrawidyakso-sh-12-7) diakses 12/7/2019
} 
Menurut Tafsir Ibnu Katsir maksudnya adalah, jadilah kalian sebagai penegak kebenaran karena Allah, bukan karena manusia atau popularitas. Dan jadilah kalian 'saksi yang adil', Maksudnya, secara adil, bukan secara curang.

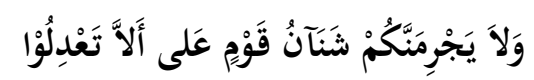

''Dan janganlah sekali kali kebencianmu terhadap suatu kaum mendorongmu untuk berlaku tidak adil." Maksudnya, janganlah kebencianmu kepada suatu kaum menjadikan kalian berbuat tidak adil terhadap mereka, tetapi tetapkanlah keadilan itu pada setiap orang. Baik itu teman atau musuh kalian. Oleh karena itu Allah berfirman "'Berlaku adil lah karena adil itu lebih dekat karena takwa'. Maksudnya, keadilan kalian itu lebih dekat kepada takwa daripada meninggalkannnya.

Firmannya: هُوَ أَقْرَبُ لِلَتَّقُوى

"Karena keadilan itu lebih dekat kepada takwa' adalah termasuk dalam kategori ' $f i$ 'lu tafdhil", yaitu kedudukan di tempat yang tidak terdapat perbandingannya.

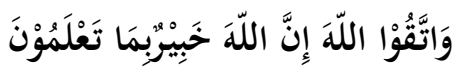

''Dan bertakwalah kepada Allah, sesungguhnya Allah maha mengetahui apa yang kamu kerjakan"'

Maksudnya Allah akan memberikan balasan kepada kalian berdasarkan ilmunya terhadap perbuatan yang kalian kerjakan, jika baik akan dibalas kebaikan dan jika buruk maka akan dibalas dengan keburukan pula. ${ }^{19}$

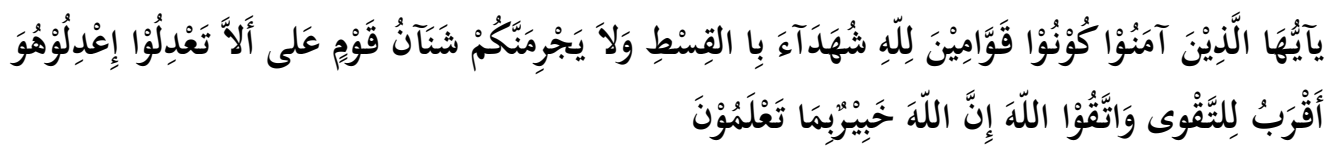

Artinya: 'Hai orang orang yang beriman ! jadilah kamu sebagai penegak keadilan karena Allah, (ketika) menjadi saksi dengan adil. Dan janganlah kebencianmu terhadap suatu kaum mendorong kamu untuk berlaku tidak adil. Berlakulah adil lah. Karena (adil) itu lebih dekat kepada takwa. Dan bertakwalah kepada Allah, sungguh Allah maha teliti terhadap apa yang kalian kerjakan."

Menurut tafsir at- Thabariy, Abu Ja'far berkata: maksudnya adalah ''wahai orang orang yang beriman kepada Allah dan Rasulnya Muhammad Saw, hendaklah kalian mejadikan diantara akhlak dan sifat kalian adalah menegakkan kebenaran karena Allah dan hendaklah menjadi saksi yang adil terhadap musuh musuh sahabat kalian. Serta janganlah kalian berlaku jahat dalam memutus perkara dan berbuat, sehingga kalian melewati apa yang dibatasi untuk kalian berkaitan dengan musuh musuh kalian lantaran permusuhan mereka terhadap kalian. Selain itu janganlah kalian sembarangan terhadap apa yang dibatasi untuk kalian berupa hukum hukum ku dan batas batas ku terhadap sahabat sahabat kalian karena persahabatan mereka, akan tetapi berhentilah dalam semua masalah kepada batasku dan kerjakanlah perintahku. ${ }^{\mathbf{2 0}}$

\footnotetext{
${ }^{19}$ Abdullah bin Muhammad bin Abdurrahman bin Ishaq al Sheikh, Tafsir Ibnu Katsir, terj. Muhammad ghoffar E.M, jil.3 (Jakarta:Pustaka Imam As Syafi'i, 2004), h. 45

${ }^{20}$ Abu ja'far Muhammad bin Jarir Ath Thabariy, Tafsir Ath thabariy, jil.8 (Jakarta: Pustaka Azzam 2007), h. 548
} 


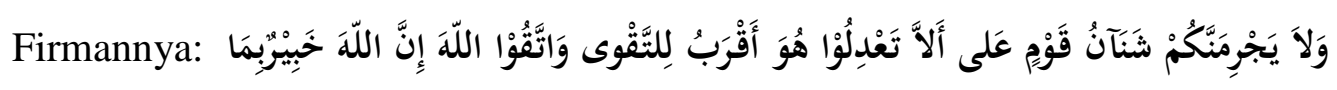
تَعْلَمُوْنَ

Maksudnya janganlah sekali kali kebencian kepada suatu kaum membawamu berbuat tidak adil dalam hukum kalian kepada mereka dan perlakuan kalian terhadap mereka, kemudian kalian berbuat jahat karena permusuhan antara kalian dengan mereka.

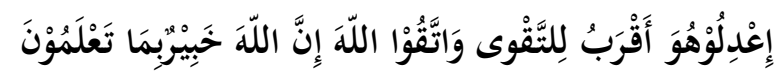

Abu Ja'far berkata: maksud firmannya, إِعْدِلُو ، 'Berlaku adil lah " adalah wahai orang orang beriman, bawalah siapapun, baik teman atau musuh, kepada hukum hukum ku dan janganlah berbuat jahat kepada salah seorang dari mereka.

Firmannya: هُو أَقْرَبُ لِلَّتَقْوى " Karena adil itu lebih dekat kepada takwa”

Maksudnya adalah " Wahai orang orang beriman, berbuat adil pada mereka lebih dekat bagi kalian kepada takwa, yakni berada di sisi Allah dengan berlaku sebagai orang yang bertakwa.

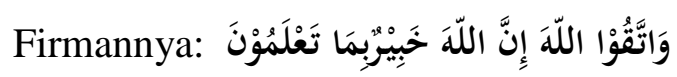

" Dan bertakwalah kepada Allah, sungguh Allah maha teliti terhadap apa yang kalian kerjakan."

Maksudnya adalah, " Waspadalah wahai orang orang yang beriman untuk berbuat jahat dalam beribadah kepadanya sehingga kalian melanggar hukum dan keputusannnya yang ada diantara kalian, kemudian kalian mendapat sisanya yang pedih.’’

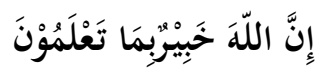

'S Sungguh Allah maha teliti terhadap apa yang kalian kerjakan'. Maksudnya adalah, "Wahai orang orang beriman, sesungguhnya Allah memiliki pengalaman dan pengetahuan atas perbuatan kalian, terhadap hal hal yang diperintahkan dan dilarang untuk kalian.Semuanya dihitung sampai dia membalas orang yang berbuat baik dengan pahalanya, dan orang orang yang berbuat buruk dengan keburukannya, oleh karena itu, takutlah untuk berbuat buruk.

Menurut tafsir al Qurthubi, firman Allah ta'ala: يَيْهَا الَّذِيْنَ آمَنُوْا كُوْنُوْا قَوَّامِيْنَ

' Hai orang orang yang beriman hendaklah kamu menjadi orang orang yang menegakkan (kebenaran)'. Makna ayat ini telah dijelaskan dalam surat an Nisa. Makna firman Allah ini adalah, aku telah menyempurnakan nikmatku untuk kalian, sehingga kalian menjadi orang orang yang selalu menegakkan kebenaran, yakni karena (menginginkan) pahala dari Allah. Oleh karena itu, tunaikanlah haknya, persaksikanlah kebenaran tanpa condong kepada kerabat kalian dan dzalim terhadap musuh kalian. ${ }^{21}$

${ }^{21}$ Al Quthubi, Tafsir Al Qurthubi, jil. 6, (Jakarta: Pustaka Azzam), h. 263

Ulumul Qur'an: Jurnal Ilmu Al-Qur'an dan Tafsir 


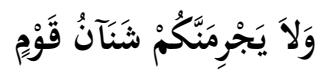

''Dan janganlah sekali kali kebencianmu terhadap suatu kaum.', Membuat (mu) tidak berlaku adil (terhadap mereka) dan lebih mengutamakan permusuhan dari pada hak. Dalam firman Allah ini terdapat dalil yang menunjukkan hukum permusuhan itu dapat berlaku terhadap hak, dalam firman Allah ini pun terdapat dalil yang menunjukkan bahwa hukum seorang musuh atas musuhnya adalah berlaku (juga). Sebab dia telah diperintahkan untuk berlaku adil, meskipun dia membenci terhadap musuhnya itu. Seandainya kesaksiannya untuk musuhnya tidak diperbolehkan, meski dia membencinya, maka perintah Allah terhadapnya agar dia berlaku adil tidak memiliki arti apapun.

Ayat ini juga menunjukkan bahwa kekafiran seorang kafir itu tidak dapat menjadi penghalang untuk berlaku adil terhadapnya. Jadi kita harus berlaku adil pada orang kafir, walaupun mereka itu musuh kita.

Makna firman Allah: هُوَ أَقْرَبُ لِلَّقْْوى " Karena adil itu lebih dekat kepada takwa" adalah, hendaklah kalian bertakwa kepada Allah. Namun menurut satu pendapat, maknanya adalah hendaklah kalian takut kepada neraka.

Dan ini merupakan penjelasan mengenai keadilan menurut al Qur'an. Ayat ini yang menunjukkan bahwa orang orang beriman diperintahkan untuk berbuat adil kepada siapapun, bahkan kepada musuh pun kita harus berlaku adil terhadapnya. Adil terhadap orang lain adalah bagaimana sesama manusia dapat saling menempatkan diri pada tempat yang layak, benar, dan sesuai dengan hak yang ia dapatkan.

Mengenai sistem ekonomi kapitalis dan sistem ekonomi sosialis, kedua sistem ini menimbulkan ketidakadilan dalam masyarakat. Dimana sistem ekonomi kapitalis yang mengutamakan individu diatas masyarakat. Memberikan kebebasan kepada setiap individunya untuk melakukan kegiatan perekonomian. Setiap individu yang bebas untuk memproduksi barang, menjual barang, dan menyalurkan barang, dan setiap individunya yang saling bersaing dalam melakukan kegiatan perekonomian.dengan seperti ini, yang kaya semakin kaya, dan yang miskin semakin miskin.

Islam mengajarkan ekonomi kerakyatan. Ekonomi kerakyatan menekankan pemerataan kemakmuran di tengah rakyat banyak. Islam mengkritik praktek kapitalisme yang mana kemakmuran hanya dapat dirasakan oleh sekelompok masyarakat. Demikian pula kritikan yang ditujukan pada sosialisme, Islam mengkritik praktek ekonomi ini karena dipandang setiap individu tidak diberi kesempatan untuk melakukan melakukan ekspresi ekonomi secara independen. ${ }^{22}$

Dan begitu juga dengan sistem ekonomi sosialis. Sistem ekonomi sosialisme meletakkan pemilikkan negara atas semua kekayaan dan alat produksi, menyebabkan manajemen seluruh alat produksi itu ada di tangan birokrasi. Perjalanan mesin ekonomi yang berlangsung secara birokratik akan berakibat pada terjadinya inefisiensi, produksi rendah, dan akhirnya meruntuhkan sistem sendiri. Selain itu, individu menjadi sulit

${ }^{22}$ Afifa Rangkuti, Konsep Keadilan Dalam Perspektif Islam, Tazkiya, Vol. 4 No. 1, (2017)

Ulumul Qur'an: Jurnal Ilmu Al-Qur'an dan Tafsir

Volume x, Nomor x, September 20xx | p-ISSN: 0000-0000; e-ISSN: 0000-000| xx-xx 
mengembangkan diri karena senantiasa dikontrol oleh negara, bahkan atas nama kepentingan Bersama hak asasi manusia sering kali terabaikan. ${ }^{23}$

Dengan begitu, ekonomi Islam hadir untuk menyelaraskan kedua sistem tersebut dalam menegakkan keadilan dengan nilai nilai Islam atau syari'at Islam.

\section{Kesimpulan}

Dalam penelitian ini dapat kita simpulkan, bahwasanya sifat adil itu harus dimiliki oleh setiap manusia untuk menegakkan kebenaran tanpa terkecuali. Dan Islam telah memerintahkan kita untuk berlaku adil terhadap sesama. Sebagaimana firman Allah SWT dalam surat al Maidah ayat 8. Allah SWT menegaskan bahwa ' 'janganlah sekali kali kebencian terhadap suatu, menjadikanmu tidak adil karena adil itu lebih dekat kepada taqwa.' Jadi, janganlah kita membenci kepada seseorang dan tidak berlaku adil terhadapnya. Sesungguhnya berlaku adil adalah jalan yang terdekat untuk mencapai tujuan bertaqwa kepada Allah. Allah yang menurunkan Islam sebagai sumber dan pedoman bagi kehidupan manusia, yang didalamnya menekankan kepada kita untuk menegakkan keadilan untuk semua termasuk kepada orang yang kita benci sekali pun.

\section{Daftar Pustaka}

Abdullah bin Muhammad bin Abdurrahman bin Ishaq al Sheikh, Tafsir Ibnu Katsir, terj. Muhammad ghoffar E.M, jil.3 (Jakarta: Pustaka Imam As Syafi'i, 2004), h. 45

Abu ja'far Muhammad bin Jarir Ath Thabariy, Tafsir Ath thabariy, jil.8 (Jakarta: Pustaka Azzam 2007), h. 548

Al Quthubi, Tafsir Al Qurthubi, jil. 6, (Jakarta: Pustaka Azzam), h. 263

Bahtiar, H. N, Hak Asasi Manusia Dalam Islam (Jakarta: Yayasan obor Indonesia, 1995), h. 128

Chalil, Zaki Fuad, Pemerataan Distribusi Kekayaan Dalam Ekonomi Islam (Jakarta: Penerbit Erlangga, 2009) h. 191 Nilai Keadilan Dalam Ekonomi Syariah: Jurnal Studi Ilmu Syariah dan Hukum Vol. 3 No. 2 (2019)

Chaudry, Muhammad Sharif, fundamental of Islamic economic system, terj. Suherman Rosyidi, Sistem Ekonomi Islam; Prinsip Dasar, (Jakarta: Kencana Prenada Media Group), h. 364

Husni, Indra Sholeh, Konsep Keadilan Ekonomi Islam Dalam Sistem Ekonomi: Sebuah Kajian Konsepsional. Islamic Economics Journal, Vol 6 No.1 (2020)

Imarah, Muhammad, Islam dan Keamanan sosial, terj. Abdul Hayyie al-Kattani (Jakarta: Gema insani press, 1998), h.116

Itang, Itang, dan Adib Daenuri. Sistem Ekonomi Kapitalis, Sosialis, Dan Islam, Tazkiya Vol 18 No.1 (2017)

\footnotetext{
${ }^{23}$ Muhammad Sharif Chaudhry, Fundamental Of Islamic Economic System, terj. Suherman Rosyidi, Sistem Ekonomi Islam; Prinsip Dasar, (Jakarta: Kencana Prenada Media Group), h. 364 
Kbbi.web.id (https://kbbi.web.id/keadilan) diakses 24/9/2021

M. Quraish Shihab, Tafsir al-Misbah, Vol 14 (Jakarta: Lentera hati, 2002), h.112-113

Putri, Marhamah Ika, Apa Itu Ekonomi Islam Dan Tujuannya: pengertian menurut para ahli, Tirto.id, (https://tirto.id/apa-itu-ekonomi-Islam-dan-tujuannyapengertian-menurut-para-ahli-gik3) diakses 23/9/2021

Rangkuti, Afifa Konsep Keadilan Dalam Perspektif Islam, Tazkiya Vol. 4 No. 1 (2017) Redy Prayuda, Wing Keadilan Ekonomi Dalam Perspektif Hukum Ilslam, Al Mustashfa Vol. 2, No. 1, (2017)

Suryani, S, Keadilan Ekonomi dalam Perspektif Ekonomi Syariah: Sebuah Tinjauan Teori, Maksimum Vol 2 No.1 (2011)

Thoin, Muhammad, Konsep Ekonomi Islam Jalan Tengah (Kapitalis-Sosialis), Jurnal Ilmiah Ekonomi Islam Vol.1, No. 3, (2015)

Wajib, Nurwino, Keadilan Dalam Konteks Perkembangan Paradigma Pembangunan, Kotaku.pu.go.id, (http://kotaku.pu.go.id:8081//wartaarsipdetil.asp?mid=8395\&catid=2\&)diaks es $26 / 10 / 2016$

Widyakso, Rendra, Konsep Keadilan Menurut Al Qur'an , badilag.mahkamahagung.go.id,

(https://badilag.mahkamahagung.go.id/artikel/publikasi/artikel/konsepkeadilan-menurut-al-qur-an-rendra-widyakso-sh-12-7) diakses 12/7/2019 